Recepción: 07/ 05 / 2018

Aceptación: 14/ 08 / 2018

Publicación: 05/ 10 / 2018

\title{
Evaluación de la capacitación en supervivencia del ecoturista en áreas naturales
}

\author{
Evaluation of the survival training of the ecotourist in natural areas
}

Avaliação do treinamento de sobrevivência do ecoturista em áreas naturais

Avaliação do treinamento de sobrevivência de ecoturistas em áreas naturais

Diana J. Nagua-Suing I

diananagua@hotmail.com

Maria E. Salazar-Quevedo II

mariaedith32@hotmail.com

Dolores M. Pezo-Ortiz III

doloresm32@hotmail.com

\section{Correspondencia: diananagua @ hotmail.com}

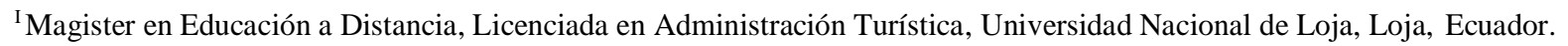

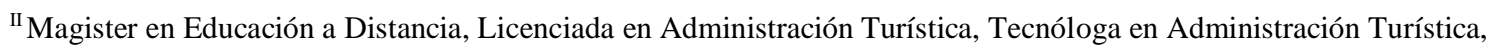

Universidad Nacional de Loja, Loja, Ecuador.

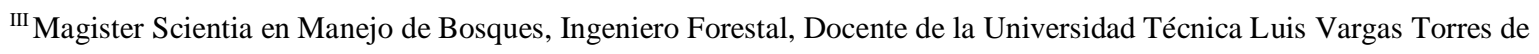




\section{Resumen}

El turismo es uno de los rubros más importantes de un país, sin embargo, la mala gestión de sus reservas naturales puede generar consecuencias irreparables para los ecosistemas. A tal efecto el presente estudio, realizo una evaluación de la capacitación en supervivencia del ecoturista que visito el área natural del humedal de la ciénaga de La Segua. La investigación fue de tipo descriptiva y de campo. Según la evolución en el tiempo se considera el estudio transeccional y la población la constituyeron 304 ecoturistas que visitaron el humedal, los resultados evidenciaron que existe la necesidad de capacitar a la población ecoturista en materia de impacto económico, social y medioambiental para lograr mantener y preservar en su estado natural los humedales de la provincia de Manabí.

Palabras clave: ecoturista; áreas naturales; humedal y supervivencia.

\section{Abstract}

Tourism is one of the most important areas of a country, however poor management of nature reserves can cause irreparable consequences for ecosystems. For this purpose, this study, conducted an evaluation of training in survival of the ecotourist visiting the wetland of La Segua swamp natural area. The research was descriptive and field. According to the evolution in time is considered the study transactional and population 304 ecotourists who visited the wetlands constituted it, the results showed that there is a need to train people ecotourist in terms of economic impact, social and environmental to maintain and preserve the wetlands in the province of Manabí in their natural state.

Keywords: ecotourist; natural areas; wetland and survival.

\section{Resumo}

O turismo é uma das áreas mais importantes de um país, no entanto, a má gestão de suas reservas naturais pode gerar consequências irreparáveis para os ecossistemas. Para tanto, o presente estudo realizou uma avaliação do treinamento de sobrevivência do ecoturista que visitou a área natural do Pantanal La Segua. A investigação foi de tipo descritivo e de campo. De acordo com a evolução temporal, considera-se o estudo transicional e a população foi constituída por 304 ecoturistas que visitaram o Pantanal, os resultados mostraram que há necessidade de capacitar a 
população ecoturística em termos de impacto econômico, social e ambiental a fim de manter e preservar em seu estado natural as terras húmidas da província de Manabí.

Palavras chave: ecoturista; áreas naturais; Pantanal e sobrevivência.

\section{Introducción}

Las áreas protegidas, como Parques Nacionales y áreas del Patrimonio Mundial de la UNESCO, conforman un gran atractivo para los turistas interesados en explorar las áreas naturales y la vida silvestre en todo el mundo. Al respecto, los visitantes de las áreas protegidas pueden convertirse en una herramienta eficaz para la conservación y el desarrollo comunitario, siempre que cuenten con sistemas de gestión buenos y funcionales. (Robyn Bushell, 2001). Según la OMT (Organización Mundial del Turismo) la definición de ecoturismo hace referencia a su finalidad, principios, elementos que lo integran, sus objetivos y los beneficios que reporta. De acuerdo con esta definición, a continuación, destacamos cuáles son las principales características del ecoturismo:

Turismo basado en la naturaleza: el objetivo es que el turista aprenda, mediante la observación de los ecosistemas, a apreciar la naturaleza que le rodea y las culturas tradicionales de dicha zona natural.

\section{Se basa en elementos como la educación ambiental o la interpretación de la naturaleza}

Solo un pequeño grupo de empresas especializadas son las que actúan como proveedores de servicios para fomentar esta modalidad de turismo. Suelen ser empresas de propiedad local.

El fin último es reducir el impacto negativo que el turismo general suele tener sobre el entorno natural, social y cultural, y de esta forma proteger las zonas naturales utilizadas como centros de atracción del ecoturismo.

Dichas características, han de han de contar con la protección integral turística que va más allá de un botiquín de primeros auxilios, se basa principalmente en la adquisición verdadera de conocimiento en materia de seguridad turística. Esto quiere decir que cuando elijes un destino turístico debes conocer toda la información que te permitirá descubrirlo, desde sus antecedentes hasta su actualidad, información económica, política y social del lugar. El conocimiento representa un arma poderosa en contra de situaciones adversas. Dentro de dicha información se 
debe manejar la ubicación geográfica de la ruta, vías alternas, atención vial por parte de las autoridades correspondiente, horarios de atención, vías de escape, tipo de flora, fauna, climas de la zona en el periodo del viaje, sucesos positivos y negativos que hayan ocurrió en el lugar, entre otras cosas.

Por ello, durante un viaje o un recorrido turístico las medidas de seguridad que se deben tomar y tener en cuenta son las que sirven para preservar la vida en esa determinada localidad, es decir, la protección integral turística se adapta a cualquier destino y es capaz de aplicarse en diferentes escalas, que en el caso particular de los Humedales, específicamente los de la ciénaga de La Segua, el cual esta estructuralmente conformada por un pantano central, que se encuentra permanentemente anegado y una extensa llanura de inundación que se cubre de agua en la estación lluviosa, es de agua dulce. Sus suelos son arenosos, limosos y/o arcillo-limosos, profundos con depósitos sedimentarios fluviales finos recientes. El agua es de calidad media, con presencia de coliformes fecales y sólidos totales, con un bajo porcentaje de oxígeno disuelto. El humedal tiene una baja diversidad de organismos, pero una alta densidad de 12 especies de peces, dos especies de camarones de río, tortugas del género Chelydra y 164 especies de aves (22 migratorias y 63 acuáticas).

La flora está representada por 27 familias y 33 especies silvestres. Durante la estación lluviosa, dominan las plantas acuáticas, especialmente los "lechuguines" (Eichhornia crassipes, jacinto de agua); la profundidad de la ciénaga puede alcanzar un promedio de 1.27 (Velásquez et al, 1997). Durante la estación seca, la planicie de inundación está repleta de hierbas y el espejo de agua se reduce a aproximadamente 525 hectáreas, con una profundidad promedio de $67 \mathrm{~cm}$. Alrededor de la ciénaga se encuentran cuatro centros poblados: San Antonio, La Segua, La Sabana y Larrea, con una población estimada de 1.700 personas. La mayor parte de este humedal corresponde a aguas abiertas, también hay grandes parches de lechuguines. En la estación seca en la llanura de inundación se cultivan hortalizas, maíz arroz, se cría ganado vacuno. También se práctica la pesca, este sitio es de importancia estratégica por los siguientes factores: a) para la conservación de varias especies acuáticas, sean estas residentes o migratorias; b) Es soporte de vida para diversidad de especies; c) Garantiza la seguridad alimentaria y provisión de agua dulce de la población que habita en los límites del humedal; d) Los humedales son considerados sumideros de carbono reduciendo el impacto del fenómeno como efecto invernadero. (MAE, 2006). Ante lo 
expuesto, en este artículo se realizó una evaluación de la capacitación en supervivencia del ecoturista en áreas naturales, que visitaron dicho humedal.

\section{Desarrollo}

Conservar las áreas naturales, con su flora y su fauna, ayuda a preservar el importante material genético para el futuro de las especies silvestres de nuestro país; además el uso adecuado de nuestros recursos naturales, permite la base productiva y los procesos que garantizan la vida; ya que, de lo contrario, la degradación de los recursos naturales conllevaría a pérdidas económicas para el país. Conservar la naturaleza y los recursos naturales son una de las necesidades más urgentes para la supervivencia de la humanidad.

La principal diferencia entre turismo y ecoturismo es que este último satisface las necesidades de las zonas ambientales. Mientras que el turismo de masas da poca importancia a su impacto en el ambiente o la cultura del lugar de destino, el ecoturismo aboga por los viajes ambientalmente responsables

\section{Impactos de la actividad turística}

La actividad turística genera impactos positivos o negativos sobre un destino, región, sitio, país donde se desarrolla. De allí, que el gran desafío que tenemos es como evitar o minimizar los impactos negativos y maximizar los impactos positivos, entendiendo que los impactos pueden ser analizados desde las dimensiones de los impactos económicos, sociales y ambientales.

Impactos económicos. El ecoturismo tiene un impacto económico como sector particular y como parte de la actividad turística en general. Por su naturaleza, el ecoturismo estimula, a la vez que da cabida al nacimiento de micro, pequeños y medianos negocios, tanto rurales como urbanos. Según Sancho (1998), los impactos económicos negativos de la actividad turística son aquellos derivados de los costes provocados por las fluctuaciones de la demanda turística, la inflación derivada de la actividad turística y las distorsiones en la economía local. Todos estos son impactos del turismo en general, y como tal, son aplicables también de forma particular al ecoturismo. Asimismo, Cañaveral (2007) explica que los beneficios financieros reportados por esta tipología turística no deben recaigan sobre la zona y la comunidad local y para evitarlo habla 
de implementar una buena gestión que tenga como finalidad básica la conservación de la sostenibilidad ambiental

Impactos sociales. Para algunos investigadores como Wearing y Neil (2000), Pérez de las Heras (2002) y Cañaveral (2007), existen diversos problemas provocados por las visitas de los turistas a un destino, entre las que se pueden mencionar:

Aparición de diferencias socioculturales entre la población residente y los turistas.

Escasa posibilidad de intervención en la toma de decisiones de la puesta en marcha del ecoturismo por parte de las comunidades locales.

Falta de reconocimiento en la labor desarrollada por parte de la población residente.

Necesidad de instrumentos que permitan una adecuada evaluación de los diversos impactos ambientales y socio-culturales que se puedan generar en el destino.

Peligro de establecer la actividad turística como el único sector económico en el área geográfica, provocando impactos negativos en otros sectores económicos del destino.

Aceleración de los cambios sociales de la población residente en el destino ecoturístico.

Falta de obtención de beneficios económicos y sociales de los proyectos desarrollados en el área geográfica.

Impactos medioambientales. El turismo ecológico como actividad turística que se desarrolla en zonas naturales, puede generar diversos daños en el medio ambiente, debido a la fragilidad de los ecosistemas. En este sentido, según Pérez de las Heras (2002), los impactos negativos hacia el medio natural producidos por el turismo son muy diversos. Los cuales según Cañaveral (2007), se pueden mencionar los propios de infraestructuras, los causados por las actividades propias de los ecoturistas y provocados por el número de visitantes en un determinado lugar al mismo tiempo. Además, la emisión de gases provocados por los medios de transportes, debido a que emiten sustancias tóxicas y perjudiciales para todos los seres vivos que habitan y visitan la zona. Se destaca también, la modificación de la flora y fauna y la explotación de agua y energía. 


\section{Metodología}

La presente investigación, fue de tipo descriptiva y de campo. Según Arias (2012), la descripción se caracteriza por describir la estructura o comportamiento de la variable estudiada tal como se presenta, y de campo debido a que la información se recogió en el lugar donde dieron los acontecimientos: Humedales, de la ciénaga de La Segua. Por otra parte, según la evolución en el tiempo se considera el estudio transeccional, debido a que la información fue recogida en un momento específico. La población la constituyeron 304 ecoturistas que visitaron el humedal, los resultados se presentan en tablas con sus respectivos análisis.

\section{Resultados}

A continuación, se presenta el análisis de los resultados obtenidos en turistas que visitaron uno de los principales humedales de la provincia de Manabí como sitio de conservación, la ciénaga de La Segua (cantones Chone y Tosagua).

En cuanto al impacto económico de supervivencia del ecosistema, según el $88 \%$ de los investigados coincidieron en opinar que los beneficios financieros reportados por esta tipología turística no se revierten sobre la zona y la comunidad local. Por otro lado, el $65 \%$ indico que se realizan actividades turísticas permanentes y que solo son permitidas en determinadas épocas del año y el 56\% expreso preocupación por la seguridad manifiesta en hurtos a turistas, así como el riesgo de contagios por virus y/o enfermedades.

El impacto social de sobrevivencia, para el $77 \%$ de los turistas se reflejan en las diferencias de cultura que debe enfrentar el turista con los residentes de los humedales, el 59\% indico la escasa posibilidad de las comunidades en materia de intervención para poner en marcha el ecoturismo local, mientras que el $82 \%$ señalo a la falta de reconocimiento de la labor desarrollada por parte de la población residente

Para los impactos medioambientales de sobrevivencia, 83\% indico que el turismo no controlado hace daño al medio ambiente debido a la fragilidad de los ecosistemas. Por su parte el $67 \%$ considera que o deben realizarse construcciones de infraestructuras, colocar equipamientos y prestar servicios sin estudio previo del deterioro que puede ocasionar en las áreas naturales del humedal. 


\section{Conclusiones}

Se pudo evidenciar, la necesidad de capacitar a la población ecoturista en materia de impacto económico, social y medioambiental para lograr mantener y preservar en su estado natural los humedales de la provincia de Manabí

Se constató negación para retribuir los ingresos para el mantenimiento y conservación de los humedales, lo que puede ocasionar costes provocados por las fluctuaciones de la demanda turística, inflación derivada de la actividad turística y distorsiones en la economía local.

Existe poco reconocimiento gubernamental de la labor que realizan las comunidades residentes en los humedales, contribuyendo a una inadecuada evaluación de los diversos impactos ambientales y socio-culturales que se puedan generarse, permitiendo a las actividades turísticas como el único sector económico para el área, ello puede provocar impactos negativos en otros sectores económicos del área.

\section{Referencias Bibliográficas}

Arias, F. (2012). El proyecto de investigación. Introducción a la metodología científica. 6ta. Edición. Venezuela. Ediciones Fidias.

Cañaveral, I. (2007). Ecoturismo en las Reservas de la Biosfera. Granada: Universidad de Granada.

MAE (2006). Plan Estratégico del Sistema Nacional de Áreas... - Mae Transparente. Recuperado en:

https://www.google.co.ve/search?q=MAE\%2C+2006\&oq=MAE\%2C+2006\&aqs=chrome.69i57. 2180j0j7\&sourceid=chrome \&ie $=$ UTF-8

OMT. (2002) El mercado español del ecoturismo. Madrid: Organización Mundial del Turismo.

Pérez de las Heras, M. (1999) La guía del ecoturismo o cómo conservar la naturaleza a través del turismo. Madrid: Mundi Prensa.

Robyn Bushell (2001). Tourism Research in Australia. Recuperado en: https://www.google.co.ve/search?q=Robyn+Bushell\&oq=Robyn+Bushell\&aqs=chrome.69i57.18 $51 \mathrm{j} 0 \mathrm{j} 7 \&$ sourceid=chrome $\& \mathrm{ie}=\mathrm{UTF}-8$ 
Sancho, A. (1998) Introducción al turismo. Madrid: Organización Mundial del Turismo.

Velázquez, M., Burgos M., Zambrano N. y Gastezzi P. (1997). Visión global de La Segua, “Un humedal del Ecuador". La Ciénaga de La Segua, guía de conocimiento y manejo. Programa de las Naciones Unidas para el Medio Ambiente (PNUMA), Programa de Manejo de Recursos Costeros (PMRC), Informe técnico interno. Guayaquil - Ecuador.

Wearing, S. y Neil, J. (2000) Ecoturismo. Impacto, tendencias y posibilidades. Madrid: Síntesis. 